\title{
Electrical Conductivity in Doped Zirconia Systems: Beyond Arrhenius Theory
}

\author{
Kleber C. Mundim \& Maria S. P. Mundim
}

Este artigo aborda o tema condutividade elétrica em sistemas de zircônio dopado, que é um importante problema não resolvido na física da matéria condensada. Embora os fenômenos de transporte em zircônio dopado sejam geralmente tratados pela teoria de van't Hoff- Arrhenius, no qual se prevê que o logaritmo da taxa de transporte é uma função linear do inverso da temperatura e que a energia de ativação é constante , muitos experimentos indicam uma não dependência de Arrhenius da temperatura. Nesses materiais, o logaritmo da condutividade elétrica quando graficada em função do inverso da temperatura absoluta, apresenta um desvio negativo da linearidade. Observando, a partir desse problema, o principal objetivo deste artigo é propor uma alternativa de aproximação para descrever a dependência da temperatura com a energia de ativação de difusão, assim como a condutividade não- Arrhenius para os sistemas $\left(\mathrm{ZrO}_{2}\right) 1-\mathrm{x}\left(\mathrm{Y}_{2} \mathrm{O}_{3}\right) \mathrm{x}$. Além disso, o presente estudo fornece novos insights sobre os desvios da linearidade em muitos fenomenos não- Arrhenius, tais como processos não exponenciais.

Palavras-chave: $d$-Arrhenius; eletrólitos sólidos de zirconio dopado; condutividade iônica.

This paper deals with the subject of electrical conductivity in doped zirconia systems, which is an important unsolved problem in condensed matter physics. Although transport phenomena in doped zirconia are usually dealt with in van't Hoff-Arrhenius theory, which predicts that the logarithm of the rate transport is a linear function of the inverse of the temperature and the activation energy is constant, many experimental researchers have recently reported non-Arrhenius temperature dependency. In these materials the logarithm of the electrical conductivity, plotted against the reciprocal of the absolute temperature, exhibits a negative deviation from linearity. In the light of existing problems in this subject, the main objective, in this article, is to propose an alternative approach to describe temperature-dependence for diffusion activation energy, as well as non-Arrhenius conductivity in $\left(\mathrm{ZrO}_{2}\right)_{1-\mathrm{x}}\left(\mathrm{Y}_{2} \mathrm{O}_{3}\right) \mathrm{x}$ systems. Furthermore, the present study provides new insights into the deviations from linearity in many non-Arrhenius phenomena, such as non-exponential processes.

Keywords: d-Arrhenius; doped zirconia solid electrolytes; ionic conductivity. 


\section{Introduction}

Linearity in empirical Arrhenius plots $(\log \sigma \times 1 / \mathrm{T})$ can be enforced because the number and accuracy of experimental data points are usually not too high. Also, in most situations involving physical and chemical ion transport processes, the accessible range of the $1 / \mathrm{T}$ variable is small. Currently, the improvement in experimental techniques to study reaction mechanisms and ionic transport has allowed measurements to be made with high accuracy and in a wide range of temperatures. In these cases, the obtained results clearly indicate a nonlinear variation between the activation energy and temperature. On the other hand, the diffusion barrier or activation energy is usually assumed constant, and there are no well-defined models that enable a correct characterization of these phenomena. In particular, for the transport mechanism in doped zirconia, there is increasing evidence from a variety of recent studies on the temperature dependence of diffusivity processes that points to the need to account for deviations from the Arrhenius mechanism. ${ }^{1-15}$ Our focus on these questions is to propose a new approach, based on a generalization of Tolman's activation energy definition $^{16}$ and van't Hoff-Arrhenius theory ${ }^{17,18,19}$, which provides a possible insight into the observed deviations from linearity and a tool for extrapolating observations beyond the experimentally accessible range in the case of ion diffusion.

Electrical conductivity in $\left(\mathrm{ZrO}_{2}\right)_{1-\mathrm{x}}\left(\mathrm{Y}_{2} \mathrm{O}_{3}\right)_{\mathrm{x}}$ systems is part of this set, and we show how its features can be described from a new perspective. These materials are recognized as part of a very important class of solid state electrolytes, $\mathrm{ZrO}_{2}-\mathrm{Ln}_{2} \mathrm{O}_{3}$ ( $\mathrm{Ln}$ meaning lanthanides); $\mathrm{Y}_{2} \mathrm{O}_{3}$-doped zirconia has many applications, such as widespread use as an electrode in oxygen sensors. The conductivity temperature-dependence of solid solutions of $\mathrm{Y}_{2} \mathrm{O}_{3}$ in $\mathrm{ZrO}_{2}$ with cubic structure was studied by Arachi et al.1 and it was determined that the Arrhenius plots of a series of mixtures with different compositions $\left(\left(\mathrm{ZrO}_{2}\right) 1-\mathrm{x}\left(\mathrm{Y}_{2} \mathrm{O}_{3}\right)_{\mathrm{x}}, \mathrm{x}=0.10,0.11,0.12,0.13,0.14,0.15\right)$ do not behave linearly. The curvatures are attributed to the dissociation of the pair dopant - vacant site and the activation energy of the process of the conduction of oxide ions is partitioned into two contributions, the associated binding energy, related to the dopant and vacant site, and the migration energy through the material. ${ }^{2}$

\section{Methodology}

In Tolman's definition the activation energy or diffusion barrier is a phenomenological quantity defined in terms of the slope of an Arrhenius plot; it is usually assumed to be independent of temperature, requires only local equilibrium and in general it is given by

$$
E_{o}=-\frac{\partial \ln \sigma(T)}{\partial\left(\frac{1}{R T}\right)},
$$

where $\mathrm{E}_{\mathrm{o}}$ is constant, $\sigma$ is the reaction rate and $\mathrm{R}$ is the ideal gas constant.

To generalize Tolman's definition, in the case of electrical conductivity, we assume that the diffusion barrier or activation energy is a function of the temperature given by the following differential equation,

$$
E_{a}=-\frac{\partial \ln \sigma(T)}{\partial\left(\frac{1}{R T}\right)}=\frac{1}{f} \frac{\partial f}{\partial\left(\frac{1}{R T}\right)} \equiv-E_{o} f^{-d},
$$

where $\sigma(T)=\sigma_{\mathrm{o}} \mathrm{f}(T)$ is the conductivity, $\sigma_{\mathrm{o}}$ is the preexponential factor, $\mathrm{f}(T)$ is a temperature dependence function and $d$ is a phenomenological real number. One possible solution for this differential equation is the function $f(T)=\left(1-d \frac{E_{0}}{R T}\right)^{\frac{1}{d}}$, name d here the d-exponential function. It is interesting to note that this result could be understood as a deformation of Euler's exponential function, that is, $\exp \left(-\frac{E_{0}}{R T}\right)=\lim _{d \rightarrow 0}\left(1-d \frac{E_{0}}{R T}\right)^{\frac{1}{T}}$. Integrating Eq.(2) we get the following equation for deformed conductivity,

$$
\sigma_{d}(T)=\sigma_{o} f(T)=\sigma_{o}\left(1-d \frac{E_{o}}{R T}\right)^{\frac{1}{d}}
$$

Following the generalized Tolman definition presented in Eq. (2) and considering the function $\mathrm{f}(\mathrm{T})$ the activation energy $\left(E_{a}\right)$ is given by 


$$
E_{a} \equiv-\frac{\partial \ln \sigma_{d}(T)}{\partial\left(\frac{1}{R T}\right)}=E_{o}\left(1-d \frac{E_{o}}{R T}\right)^{-1}
$$

where $\mathrm{E}_{\mathrm{a}}=\mathrm{E}_{\mathrm{o}}$ and $\sigma_{\mathrm{d}}=\sigma_{\mathrm{o}}$ at limit $\mathrm{d} \rightarrow 0$. Thus a positive convexity means that $\mathrm{E}_{\mathrm{a}}$ decreases with increasing temperature. This general result is explained by Tolman's interpretation of the activation energy. ${ }^{16}$ It is important to point out that when the temperature (T) goes to infinity, the usual Arrhenius law expression is recovered, i.e. $\sigma(T)=\lim _{d \rightarrow 0} \sigma_{o}\left(1-d \frac{E_{0}}{R T}\right)^{\frac{1}{d}}=\sigma_{o} e^{\frac{E_{0}}{R T}}$. . In this approach the parameter $d$ has a central role. It is believed that processes with negative values of $\mathrm{d}$ have a mechanism that involves tunneling and are labeled sub-Arrhenius, while those with positive values have diffusion as a predominant part of the mechanism and are denominated super-Arrhenius. These features were verified by different chemical and biophysical processes. ${ }^{19-21}$

One of the most remarkable aspects of this proposal is that it is related to a non-Boltzmann distribution law of the non-extensive thermodynamics proposed by Tsallis ${ }^{22,23}$, where the parameter $d$ is equivalent to $1-q$ of this reference. The great advantage in adopting this path, therefore, is that only three parameters are needed to fit the experimental data, while other approaches usually use more, which can be rather troublesome.

\section{Results and Discussion}

In this study, we will present the application of the proposed approach to study the oxide ion conductivity of $\mathrm{Y}_{2} \mathrm{O}_{3}$-doped zirconia. Before beginning the discussion of the results, it is important to mention that the experimental data were extracted from Arachi's paper. ${ }^{1}$ The chosen systems had cubic structure and due to the difficulties to extract the data points in the range of 700 to $1000 \mathrm{~K}$, we decided to use only the plots of the solutions with concentration higher than $10 \mathrm{~mol} \%$, as it is difficult to discriminate the points at lower concentration. It is important to note that all plots converge to a similar situation at high temperatures and this is a very relevant feature: it means that at higher temperatures, the dopant-vacant site interaction is reduced. The results are plotted in Fig. (1).

The experimental $\left(\log \sigma_{\text {exp }}\right)$ data were fitted to a deformed conductivity function $\left(\log \sigma_{d}\right)$ using the following procedure:

I First, we select the experimental data for the electrical conductivity for one specific composition of the mixture $\left(\left(\mathrm{ZrO}_{2}\right)_{1}-\mathrm{x}\left(\mathrm{Y}_{2} \mathrm{O}_{3}\right) \mathrm{x}\right.$, where $\mathrm{x}=0.10$, $0.11,0.12,0.13,0.14,0.15)$;

II Next, we use the Generalized Simulated Annealing (GSA) procedure 24 to find the parameters $\sigma_{o}$, E_o and $d$ that fit the experimental data using the following chi-square definition:

$$
\chi^{2}=\sum_{k=1}^{N}\left[\log \sigma_{\text {exp }}\left(T_{k}\right)-\log \sigma_{d}\left(T_{k}\right)\right]^{2},
$$

where $\mathrm{N}$ is the number of points in the experimental data and $\mathrm{T}_{-} \mathrm{k}$ is the absolute temperature.

III The GSA procedure runs until the chi-square is reached within the desired precision, and in this paper the precision established is $\chi^{2}<10^{-4}$.

Tabela 1. $\sigma_{o}, d, E_{o}$ are the phenomenological parameters and $E_{a}$ is the activation energy at $\mathrm{T}=300 \mathrm{~K}$.

\begin{tabular}{|c|c|c|c|c|}
\hline $\mathbf{x}$ & $\mathbf{d}$ & $\boldsymbol{\sigma}_{\mathbf{0}}\left(\mathbf{S . c m}^{-\mathbf{1}} \mathbf{. K}\right) \times\left(\mathbf{1 0}^{\mathbf{}}\right)$ & $\mathbf{E}_{\mathbf{0}}(\mathbf{J} / \mathbf{m o l})$ & $\mathbf{E}_{\mathbf{a}}(\mathbf{J} / \mathbf{m o l})$ \\
\hline 0.10 & 0.0447 & 0.1496 & 62.310 & 62.380 \\
\hline 0.11 & 0.0379 & 0.2707 & 69.597 & 69.670 \\
\hline 0.12 & 0.0342 & 0.3870 & 75.320 & 75.394 \\
\hline 0.13 & 0.0298 & 0.3239 & 80.280 & 80.357 \\
\hline 0.14 & 0.0259 & 0.3417 & 84.127 & 84.201 \\
\hline 0.15 & 0.0211 & 0.6616 & 94.139 & 94.215 \\
\hline
\end{tabular}




\section{Artigo Convidado 2}

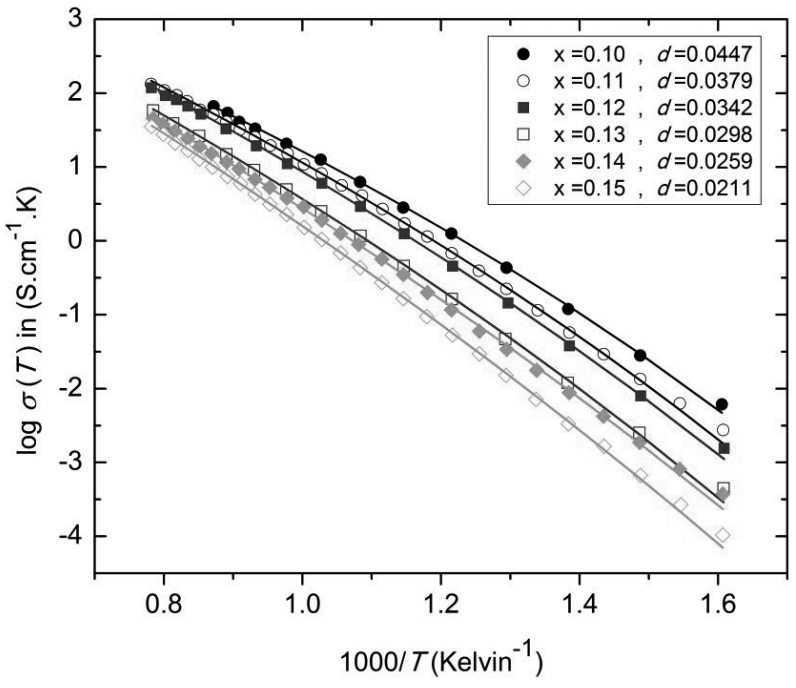

Figure 1. Electrical conductivity plots using the proposed approach and for different concentrations $(\mathrm{x})$ of $\left(\left(\mathrm{ZrO}_{2}\right)_{1-\mathrm{x}}\left(\mathrm{Y}_{2} \mathrm{O}_{3}\right) \mathrm{x}\right.$, where $\mathrm{x}=0.10$, $0.11,0.12,0.13,0.14,0.15$. The points represent the experimental data and the solid lines are our model fitted to the measured conductivity.

It comes as no surprise to see that these are super-Arrhenius processes $(d>0)$, since the measurement of electrical conductivity requires the flow of electric charges, which is a transport phenomenon. Another important feature is related to the activation energy, where $\mathrm{E}_{\mathrm{b}}$ is the associated binding energy and E_m the migration energy. In the d-Arrhenius approach, there is no need for this partitioned description. Since natural events hardly ever exhibit purely linear behaviors, it can be stated that $\mathrm{E}_{\mathrm{b}}$ and $\mathrm{E}_{\mathrm{m}}$ are correlated and the activation energies follow relations such as those seen in Eq. (5).

A striking feature observed is the dependence that the deformation parameter $d$ has on the concentration of the dopant (Fig. 2). The data suggests that parameter $d$ is a linear function of the $\mathrm{Y}_{2} \mathrm{O}_{3}$ concentration.
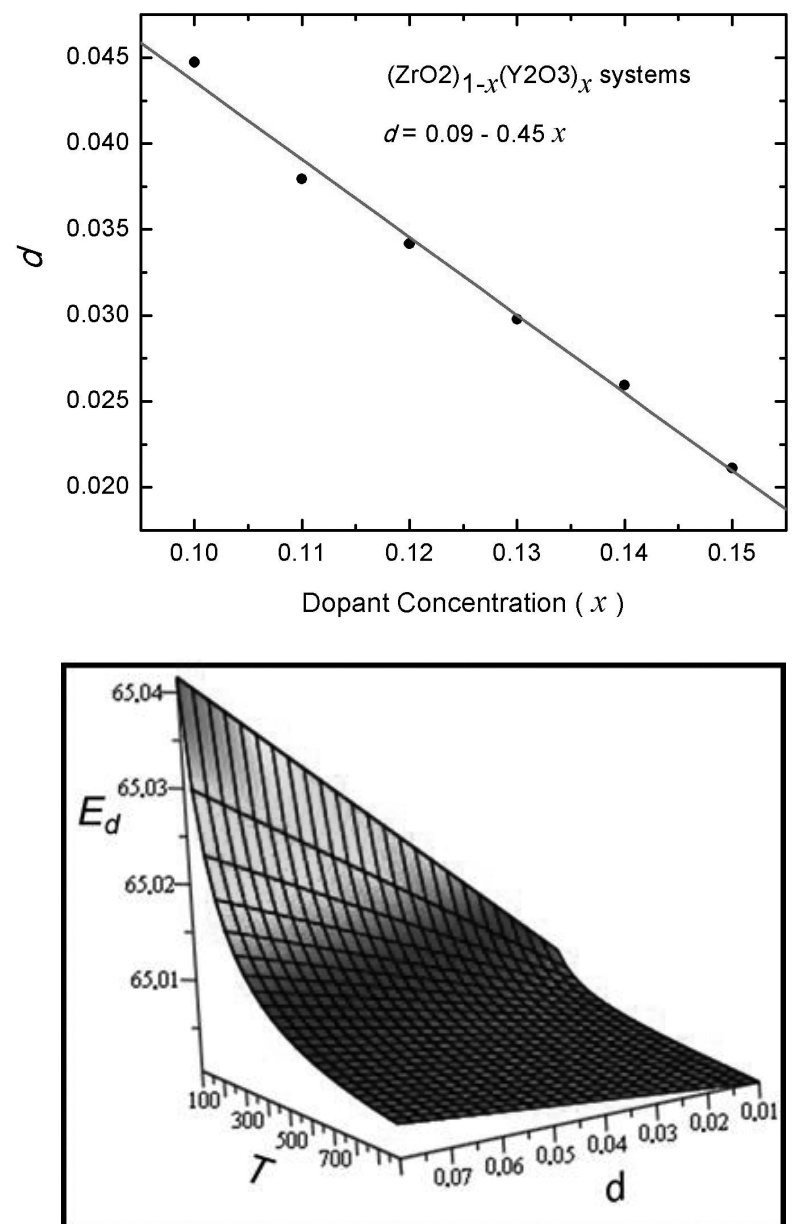

Figure 2. (a) Linear dependence of $d=0.09-0.45 x$ parameter on the concentration ( $\mathrm{x})$ of $\left(\mathrm{ZrO}_{2}\right)_{1-\mathrm{x}}\left(\mathrm{Y}_{2} \mathrm{O}_{3}\right)_{\mathrm{x}}$. The black dots were obtained through fitting the $\log \sigma \times 1 / \mathrm{T}$ over the experimental data showed in the Fig.1. (b) Typical plots using the proposed approach were based on generalized Tolman's activation energy $\left(\mathrm{E}_{\mathrm{a}}\right)$ showing deviations from the linearity described by the d parameter. We can observe, in Fig.2 (b), that at limit $\mathrm{d} \rightarrow 0$, the activation energy should be a constant and temperature independent.

There has been some discussion upon the meaning of $\mathrm{d}$, since, under a simple examination, it appears to be another parameter used to improve the fit. The plot in Fig. 2 (a) shows a correlation between those quantities 
and suggests $d$ must have some physical interpretation, perhaps associated with the disposition of the dopant ions in the crystal structure. In this application $d$ is a linear function of the dopant concentration (x). The results plotted in Fig. 2(b) show that the activation energy is not constant in this conductivity process.

\section{Conclusions and Remarks}

Very recent reviews in the scientific literature, including the references therein, examine how electrical conductivity in doped zirconia works, especially when experiments can be carried out over a wide range of temperatures, preferably including low ones. In particular, the ionic conductivity or transport phenomena for most rate processes depend on absolute temperature $\mathrm{T}$ according to the Arrhenius or exponential law. When extended to low temperatures, deviations from Arrhenius law are observed even with no apparent changes in the transport mechanism or in the physical nature of the moieties (e.g. their phase). The phenomenological description individuates, convex or concave $\log (\sigma) \times 1 / \mathrm{T}$ plots, as sub-Arrhenius or super-Arrhenius regimes; they correspond, respectively, to higher or lower conductivity as temperature decreases, and therefore to a decrease or increase in the apparent activation energy. Recent systematic investigations ${ }^{19,25}$ have led to a simple formalism in terms of a single deformation parameter, $\mathrm{d}$, which is inspired by Tsallis nonextensive statistical mechanics and exploits Euler's limit of the exponential function. Formally, the parameter accounts for positive or negative linear dependence of the inverse of activation energy against $1 / \mathrm{T}$ and reasonably covers both regimes uniformly. However, they are in general very different in nature. Evidence is being accumulated that in the vast majority of cases sub-Arrhenius behavior arises because of quantum mechanical tunneling, while super-Arrhenius often manifests because of collective phenomena and covers on ample set of phenomena (such as transport, diffusion, those responsible for catalysis, both enzymatic and heterogeneous). In order to distinguish the concave or convex regime the proposed methodology in this work seems to be a useful tool. In particular, as showed before, the electrical conductivity in doped zirconia belongs to the convex Arrhenius and exhibits a negative deviation from linearity, see for example Fig.(1). For the convex Arrhenius case there will be deviations from the simple Arrhenius equation in the sense that the apparent activation energy will decrease with decreasing temperature. The obtained results show how d-Arrhenius theory can be successfully applied to describe the temperature-dependence of electrical conductivity and to demonstrate that $\mathrm{d}$ is not just another parameter and can, indeed, have a physical interpretation. It was shown that the deformed exponential fits the experimental points very well and that important information can be inferred from the fitted curves: the activation energy can be described more uniformly, and the parameter $\mathrm{d}=0.09-0.45 \mathrm{x}$ can have a physical meaning, which is proportional to the dopant concentration (x), as seen in Fig.2 (a). It is important to highlight that at the limit $\mathrm{d} \rightarrow 0$, the $d$-Arrhenius approach recovers the usual van't Hoff-Arrhenius law, which provides somewhat higher flexibility and enables extrapolation to more extended ranges of temperature. This is particularly evident in Fig.2 (b), where the activation energy decreases with the temperature, while an asymptotically correct behavior is described by the new approach. It is noteworthy that the success of this fitting procedure is, in part, due to the d-exponential function's flexibility given by the $\mathrm{f}(\mathrm{T})$ function.

\section{Acknowledgements}

The author thanks the Conselho Nacional de Desenvolvimento Científico e Tecnológico (CNPq) and Coordenação de Aperfeiçoamento de Pessoal de Nível Superior (CAPES) for the support provided for this work.

\section{References}

1. Arachi, Y.; Sakai, H.; Yamamoto, O.; Takeda, Y.; Imanishai, N. Solid State Ionics 1999, 121, 133.

2. Kilner, J. A.; Brook, R. J. Solid State Ionics 1982, 6, 237.

3. Chavan, S. V.; Singh, R. N. J Mater Sci 2013, 48, 6597.

4. de Carvalho, E.; Preis, W.; Sitte, W.; Irvine, J. T. S. Solid State Ionics 2010, 181, 1344.

5. Preis, W.; Waldhausl, J.; Egger, A.; Sitte, W.; de Carvalho, E.; Irvine, J. T. S. Solid State Ionics 2011, 192, 148.

6. Singh, V.; Babu, S.; Karakoti, A. S.; Agarwal, A.; Seal, S. J Nanosci Nanotechno 2010, 10, 6495. 


\section{Artigo Convidado 2}

7. Li, W. Y.; Gong, M. Y.; Liu, X. B. J Power Sources 2013, 241, 494.

8. Raj, E. S.; Atkinson, A.; Kilner, J. A. Solid State Ionics 2009, 180, 952.

9. Hui, S. Q.; Roller, J.; Yick, S.; Zhang, X.; Deces-Petit, C.; Xie, Y. S.; Maric, R.; Ghosh, D. J Power Sources 2007, 172, 493.

10. Joo, J. H.; Choi, G. M. Solid State Ionics 2008, 179, 1209.

11. Fontecave, T.; Sanchez, C.; Azais, T.; Boissiere, C. Chemistry of Materials 2012, 24, 4326 .

12. Kazlauskas, S.; Kezionis, A.; Salkus, T.; Orliukas, A. F. Solid State Ionics 2013, 231, 37.

13. Raghvendra; Singh, P.; Singh, R. K. Journal of Alloys and Compounds 2013, 549, 238 .

14. Tokiy, N. V.; Perekrestov, B. I.; Savina, D. L.; Danilenko, I. A. Phys. Solid State 2011, 53, 1827.

15. Abbas, H. A.; Argirusis, C.; Kilo, M.; Wiemhofer, H. D.; Hammad, F. F.; Hanafi, Z. M. Solid State Ionics 2011, 184, 6.

16. Tolman, R. C. Journal of the American Chemical Society 1920 , 42, 2506.

17. van't Hoff, J. H. Etudes de Dynamique Chimique; Frederik Muller 4\& Co.: Amsterdam, 1884.

18. Arrhenius, S. Philosophical Magazine and Journal of Science 1896, 41, 40.

19. Aquilanti, V.; Mundim, K. C.; Elango, M.; Kleijn, S.; Kasai, T. Chemical Physics Letters 2010, 498, 209.
20. Truhlar, D. G. Journal of Chemical Education 1978, 55, 309.

21. Truhlar, D. G.; Kohen, A. Proceedings of the National Academy of Sciences of the United States of America 2001, 98, 848.

22. Tsallis, C. J Stat Phys 1988, 52, 479.

23. Quapp, W.; Zech, A. Journal of Computational Chemistry 2010, $31,573$.

24. Mundim, K. C.; Tsallis, C. International Journal of Quantum Chemistry 1996, 58, 373.

25. Aquilanti, V.; Mundim, K. C.; Cavalli, S.; De Fazio, D.; Aguilar, A.; Lucas, J. M. Chemical Physics 2012, 398, 186-191.

\section{Kleber C. Mundim ${ }^{{ }^{*}}$ \& Maria P. Mundim ${ }^{\text {b }}$}

${ }^{a}$ Instituto de Química, Universidade de Brasília, Caixa Postal 4478, 70904-970 Brasília, Brazil

b Instituto de Física, Universidade de Brasília, 70919-970 Brasília, Brazil

E-mail:kcmindim@unb.br 